\title{
Atomic Spectroscopy S \\ Rapid Screening Analysis of Methylmercury in Fish Samples Using Stannous Chloride Reduction and Direct Sampling Electrothermal Vaporization Atomic Absorption Spectrometry
}

\author{
Siqi Li, ${ }^{\mathrm{a}, \mathrm{b}, \overline{\mathrm{T}}}$ Congcong Hao, ${ }^{\mathrm{b}, \overline{\mathrm{T}}}$ Peizhe Xing, ${ }^{\mathrm{a}, \mathrm{d}}$ Xiaolong Xia, ${ }^{\mathrm{c}}$ Tengpeng Liu, ${ }^{\mathrm{a}}$ and Xuefei Mao ${ }^{\mathrm{a}}$ \\ ${ }^{a}$ Institute of Quality Standard and Testing Technology for Agro-products, Chinese Academy of Agricultural Sciences, and Key Laboratory of Agro-food \\ Safety and Quality, Ministry of Agriculture and Rural Affairs, Beijing 100081, P.R. China \\ b Department of Food and Biological Engineering, Handan Polytechnic College, Handan 056001, P.R. China \\ c Inspection and Testing Center of Agricultural and Livestock Products of Tibet, Lhasa 850000, P.R. China \\ d Hebei University of Engineering, Handan 056021, P.R. China
}

Received: 10 August 2020, Revised: 7 September 2020, Accepted: 7 September 2020, Available online: 11 September 2020.

DOI: $10.46770 / A S .2020 .05 .006$

ABSTRACT: A rapid analysis of methylmercury (MetHg) in fish samples is reported by using stannous chloride reduction and direct sampling electrothermal vaporization atomic absorption spectrometry (ETV-AAS). After the simple reduction reaction using $10 \% \mathrm{SnCl}_{2}$ (w:v), $\mathrm{Hg}^{2+}$ was changed to volatile $\mathrm{Hg}^{0}$ and vaporized from the analyte extraction solution. Then, the residual $\mathrm{Hg}$ species was determined with the direct sampling $\mathrm{Hg}$ analyzer without requiring chromatographic separation. Since the dominating organic $\mathrm{Hg}$ in fish tissues is mostly MetHg (methylmercury), the measured alkyl $\mathrm{Hg}$ residue can therefore be considered to be $\mathrm{MetHg}^{+}$for rapid screening. The LOD (detection limit) of the proposed method reached $0.6 \mu \mathrm{g} / \mathrm{kg}$ of MetHg with $0.4 \%-6.3 \%$ RSD (relative standard deviation). No significant difference $(P>0.05)$ was found between the proposed method and the liquid chromatographic atomic fluorescence spectrometry (LC-AFS) method or certified values of reference materials, which proves the accuracy of the MetHg analysis in real marine and freshwater fish samples. The total testing time for one aliquot, including instrumental analysis $(\sim 3$ min) and sample preparation, can be performed within $100 \mathrm{~min}$. Considering the possible EtHg (ethylmercury) existence in most fish samples, it is suggested that this proposed method be used for future rapid screening analysis, which no doubt also offers considerable applicable potential for fast mercury speciation analysis to protect food safety.

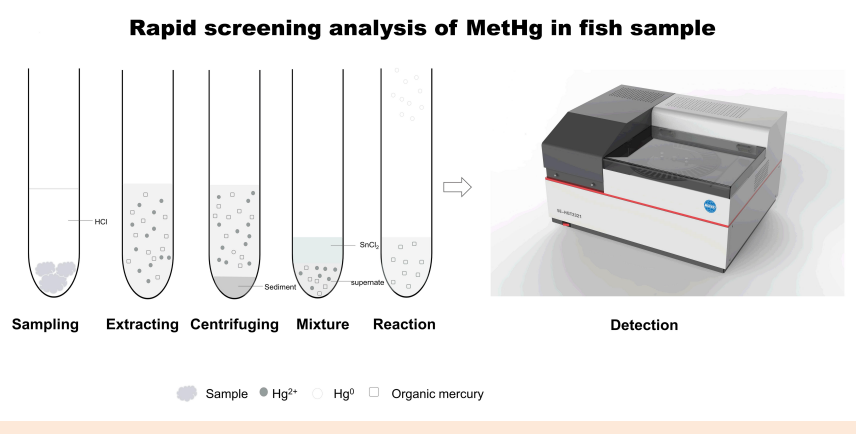

\section{INTRODUCTION}

The effects of mercury $(\mathrm{Hg})$ on the biological organisms are of great concern due to high toxicity, bioaccumulation, and persistence, once also causing the terrible Minamata disease in Japan. ${ }^{1}$ Due to industrial contamination, geological activity and other sources, $\mathrm{Hg}$ contamination in foods can be considered a constant threat to public health. ${ }^{2}$ There are different $\mathrm{Hg}$ species and their corresponding levels of toxicity require investigation. For instance, methylmercury $\left(\mathrm{MetHg}^{+}\right)$is more toxic than inorganic mercury (iHg, namely $\mathrm{Hg}^{2+}$ ) and ethylmercury $\left(\mathrm{EtHg}^{+}\right)$. To control MetHg, the FAO/WHO Codex Alimentarius Commission (CAC) has established the upper limit of $1 \mathrm{mg} / \mathrm{kg}$ MetHg for predatory fish and $0.5 \mathrm{mg} / \mathrm{kg}$ for non-predatory fish. Therefore, $\mathrm{Hg}$ speciation in fish samples should be closely monitored to ensure public health safety.

At present, most mercury speciation analysis in fish samples is performed using gas chromatography $(\mathrm{GC})^{3,4}$ or GC mass spectrometry (MS), ${ }^{5}$ liquid chromatography (LC) $)^{6-8}$ coupled with 
atomic fluorescence spectrometry (AFS), ${ }^{9,10}$ cold vapor atomic absorption spectrometry (CVAAS), ${ }^{11}$ and inductively coupled plasma optical emission spectrometry (ICP-OES) ${ }^{12}$ or inductively coupled plasma mass spectrometry (ICP-MS) ${ }^{13}$ To ensure that the $\mathrm{Hg}$ species are not altered during sample preparation, some moderate sample pre-treatments ${ }^{14}$ have always been utilized before chromatographic separation, including shaking and ultrasonic extraction using mild extractants, such as acid/alkali solutions with or without organic reagents. However, the sample preparation required for the chromatographic separation process involves extraction, separation, and purification, which are tedious and time-consuming. Even though conventional chromatographic spectrometry is a powerful technique for sensitive speciation analysis, the instrumentation is expensive, involves high operating costs, and thus is not available in smaller laboratories, especially in developing countries.

At present, the direct sampling $\mathrm{Hg}$ analyzer has become the most successful solid sampling analysis instrument. ${ }^{15-17}$ It is mainly ${ }^{15}$ composed of an electrothermal vaporizer (ETV), a catalytic pyrolysis furnace, an amalgam trap, and a detector. ETV fulfills direct introduction of the $\mathrm{Hg}$ species and matrices; catalytic pyrolysis fulfills decomposition of interfering organic components as well as atomization of $\mathrm{Hg}$ vaporized from sample; gold amalgamation via selectively trapping/releasing of $\mathrm{Hg}^{0}$ vapor fulfills matrix separation and sensitivity enhancement. Due to the excellent analytical performance, the direct sampling $\mathrm{Hg}$ analyzer has been adopted as the standard method for $\mathrm{Hg}$ analysis in water and solid samples by the United States Environmental Protection Agency (USEPA) ${ }^{18}$ It has been used to measure total $\mathrm{Hg}$ in fish, soil, oil, geological, and gas samples without acid digestion, and requires only 3-5 min for the total analytical process. ${ }^{17,19-23}$ However, to the best of our knowledge, the direct sampling $\mathrm{Hg}$ analyzer was only used to detect total $\mathrm{Hg}$ rather than the $\mathrm{Hg}$ species, and was never coupled with a speciation separation technique.

In the process of $\mathrm{Hg}$ vapor generation, stannous chloride was frequently employed as the reducing agent to react with $\mathrm{Hg}^{2+}$ to form the volatile $\mathrm{Hg}^{0}$ species for chemical vapor generation (CVG) AAS or AFS measurement under typical conditions. During this reaction, $\mathrm{Sn}^{2+}$ only reduces $\mathrm{Hg}^{2+}$ rather than alkyl mercury including $\mathrm{MetHg}^{+}$and $\mathrm{EtHg}^{+}$; so, alkyl mercury remains in the reaction system after that. Though this principle is reported for alkyl mercury analysis, ${ }^{24}$ it has not been applied to direct sampling
$\mathrm{Hg}$ analyzer. For this, we decided to match $\mathrm{MetHg}^{+}$analysis with the direct sampling $\mathrm{Hg}$ analyzer, in which the residual $\mathrm{Hg}$ species after the $\mathrm{Hg}^{2+}-\mathrm{Sn}^{2+}$ reaction should almost all be alkyl mercury. Moreover, $\mathrm{MetHg}^{+}$accounts for $70 \%-95 \%$ of $\mathrm{Hg}$ content in fish, while the $\mathrm{EtHg}^{+}$percentage is very low. ${ }^{25}$ Thus, for the purpose of rapid screening of fish samples, the residual $\mathrm{Hg}$ can be considered to be $\mathrm{MetHg}^{+}$. This subtraction strategy has been adopted to determine $\mathrm{MetHg}^{+}$coupled to cold vapor atomic absorption spectrometry (CVAAS) using liquid sampling systems, where $\mathrm{MetHg}^{+}=$total $\mathrm{Hg}-\mathrm{Hg}^{2+} .{ }^{26}$ However, this method still requires two measurements including acid digestion for total $\mathrm{Hg}$ analysis. If the direct sampling $\mathrm{Hg}$ analyzer can be applied to measure the residual $\mathrm{Hg}$ species mentioned above, the $\mathrm{MetHg}^{+}$content can be obtained directly and quickly. As a result, the analytical efficiency and speed would be significantly improved.

In this work, we utilized stannous chloride to reduce $\mathrm{Hg}^{2+}$ to volatile $\mathrm{Hg}^{0}$ and vaporize it from the analyte extraction solution. Then, the residual Hg species can be measured by direct sampling $\mathrm{Hg}$ analyzer based on ETV-gold amalgamation-AAS, regardless of chromatographic separation, and can then be considered the $\mathrm{MetHg}^{+}$presence in fish samples. After optimization, the proposed method resulted in $0.6 \mu \mathrm{g} / \mathrm{kg}$ detection limit (LOD) and $<10 \%$ relative standard deviation (RSD). The analytical performance is comparable to liquid chromatography-atomic fluorescence spectrometry (LC-AFS). This proposed analytical method, no doubt, has considerably applicable potential for fast mercury speciation analysis in small size laboratories without LC-AFS.

\section{EXPERIMENTAL}

Instrumentation. The direct sampling $\mathrm{Hg}$ analyzer (Model 5EHGT2321, Changsha Kaiyuan Hongsheng Technology Co., Ltd, Changsha, P. R. China) consists of thermal quartz tube as ETV, catalytic pyrolysis furnace, gold amalgamation, and AAS detector. The detector is equipped with a $253.7 \mathrm{~nm} \mathrm{Hg-boosted} \mathrm{hollow}$ cathode lamp (HCL) and long/short light paths for measuring low/high $\mathrm{Hg}$ concentrations, respectively. The operating parameters are listed in Table 1. $\mathrm{O}_{2}(99.999 \%, v / v)$ was employed as the carrier gas as well as the combustion-supporting gas for dehydrating and ashing sample.

Materials and Reagents. All chemicals were of superior analytical reagent grade and purchased from Sinopharm Chemical Reagent (Beijing, P.R. China), unless otherwise stated. Standard

Table 1. Programs of Direct Sampling Hg Analyzer

\begin{tabular}{llll}
\hline ETV Program & Temperature $\left({ }^{\circ} \mathbf{C}\right)$ & Hold time $(\mathbf{s})$ & $\mathbf{O}_{2}$ flow rate $(\mathrm{mL} / \mathbf{m i n})$ \\
\hline Drying & 260 & 5 & 220 \\
Ashing/vaporization & 850 & 80 & \\
Catalytic pyrolysis furnace & 600 & $/$ & \\
\multicolumn{5}{c}{ Detection } & Absorption tank clean & 120 & 15 \\
& Heating amalgam & 800 & 12 \\
& Detection furnace & 200 & 50 \\
\hline
\end{tabular}




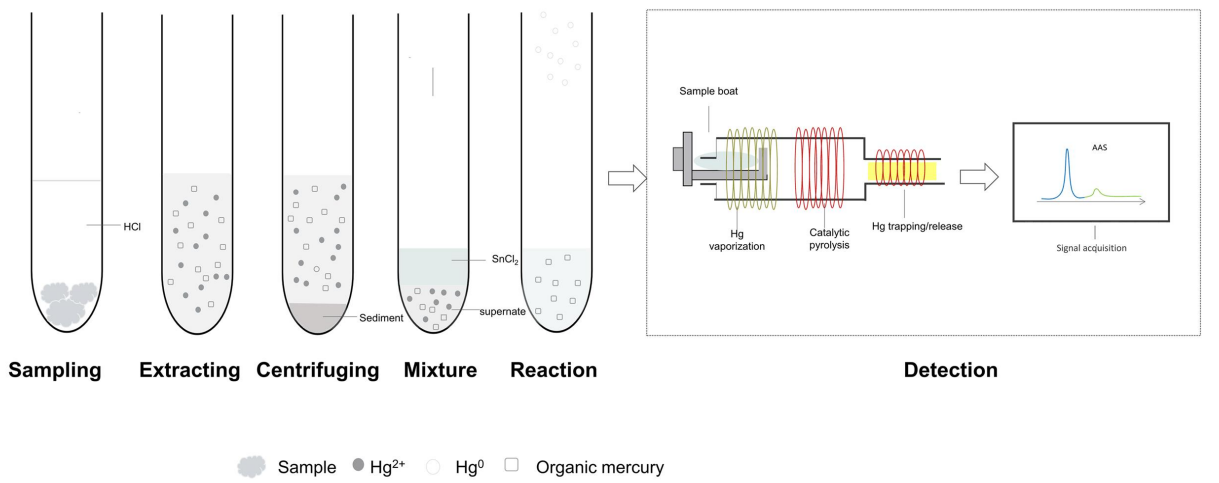

Fig. 1 The analytical schematic diagram for MetHg in fish sample by the proposed method.

stock solutions of $\mathrm{Hg}(1000 \mathrm{mg} / \mathrm{L})$ were purchased from the National Research Center for Certified Reference Materials (NRCCRM) (Beijing, P. R. China). Working standard solutions were obtained by stepwise dilution with purified water obtained from the Milli-Q integral water purification system (Millipore Corporation, USA). Certified reference material (CRM) of fish tissue sample (QC457B-2, MetHg: 507 $\pm 28 \mu \mathrm{g} / \mathrm{kg}$ ) (China SFAPA Testing Technology Company Limited of Dalian, Dalian, P. R. China) was used for method development and verification. The real fish samples were purchased at local supermarkets. These fish samples were descaled and skinned, the muscle tissue separated, and then mashed into fine paste. The mashed fish samples were pre-frozen at $-80{ }^{\circ} \mathrm{C}$ for $12 \mathrm{~h}$ (Model HYC-940, Haier Co., Ltd. Qingdao, P. R. China) and further freeze-dried for $48 \mathrm{~h}$ in a freezedryer (Virtis Genesis 25L, SP Scientific, USA). Finally, these freeze-dried samples were ground and sieved through a 60 mesh sieve.

Sample preparation and analytical procedures. The sample preparation was modified from the Chinese national standard method of GB $5009.17^{27}$ and the analytical procedures were performed as shown in Fig. 1. The detailed steps were as follows: (1) The fish samples $(0.5 \mathrm{~g})$ were weighed into a centrifugation tube. (2) $10 \mathrm{~mL} \mathrm{HCl}(5 \mathrm{~mol} / \mathrm{L})$ was added to the tube, then mixed for $1 \mathrm{~h}$ in an ultrasonic water bath at ambient temperature to assist the extraction. (3) The analyte mixture was centrifuged at 8000 $\mathrm{r} / \mathrm{min}$ for $15 \mathrm{~min}$, then $1 \mathrm{~mL}$ of the supernatant was transferred to another centrifugation tube. (4) $1 \mathrm{~mL}$ of $10 \% \mathrm{SnCl}_{2}(w: v)$ solution was added with $1 \mathrm{~mL}$ supernatant to react with $\mathrm{Hg}^{2+}$ for $15 \mathrm{~min}$ using ultrasonic water bathing at ambient temperature. The stannous chloride reaction was performed in a sealed glass box connected to a miniature vacuum pump, in which a small chamber, filled with active carbon, was fixed in the gas line between the glass box and the vacuum pump. The active carbon was replaced periodically. (5) A certain amount of the residual solution was introduced into the direct sampling $\mathrm{Hg}$ analyzer for $\mathrm{Hg}$ measurement, and for fast screening analysis since it is considered to be present as MetHg. According to the sample mass and reagent volume, the dilution factor was found to be 40 -fold.
Table 2. The Optimal Parameters for LC-AFS

\begin{tabular}{|c|c|c|}
\hline Instruments & Parameters & Values \\
\hline \multirow[t]{3}{*}{$\mathbf{L C}$} & $\begin{array}{l}\text { Reversed-phase } \mathrm{C} 18 \\
\text { column } \\
\text { Mobile phase }\end{array}$ & $\begin{array}{c}\text { Agela MP-C18 } \\
(150 \mathrm{~mm} \times 4.6 \mathrm{~mm} \\
\text { i.d., } 5 \mu \mathrm{m}) \\
5 \% \text { acetonitrile }+60 \mathrm{mM} \\
\text { ammonium acetate }+ \\
10 \mathrm{mM} \text { cysteine }\end{array}$ \\
\hline & Flow rate $(\mathrm{mL} / \mathrm{min})$ & 1.0 \\
\hline & Injection volume $(\mu \mathrm{L})$ & 100 \\
\hline \multirow{4}{*}{ HG } & Reducing agent & $\begin{array}{c}2 \% \mathrm{KBH}_{4} / 0.5 \% \\
\mathrm{KOH}(\mathrm{m} / \mathrm{v})\end{array}$ \\
\hline & Acid & $7 \% \mathrm{HCl}(\mathrm{v} / \mathrm{v})$ \\
\hline & Oxidizing agent & $\begin{array}{c}1 \% \mathrm{~K}_{2} \mathrm{~S}_{2} \mathrm{O}_{8} / 0.5 \% \\
\mathrm{KOH}(\mathrm{m} / \mathrm{v})\end{array}$ \\
\hline & UV irradiation & $19 \mathrm{~W}$ \\
\hline \multirow{7}{*}{ AFS } & $\begin{array}{l}\text { Hollow cathode lamp } \\
\text { (HCL) }\end{array}$ & $\mathrm{Hg}$ \\
\hline & PMT voltage (mV) & $270-300$ \\
\hline & HCL current (mA) & 30 \\
\hline & Carrier gas (mL/min) & 300 \\
\hline & Shield gas (mL/min) & 600 \\
\hline & Pump speed (r/min) & 35 \\
\hline & Atomization & $\mathrm{Ar} / \mathrm{H}_{2}$ diffusion flame \\
\hline
\end{tabular}

LC-AFS analysis. The LC-AFS instrument (SA-20, Beijing Titan Instrumental Co., Ltd., Beijing, P.R. China), equipped with a $\mathrm{Hg}$ hollow cathode lamp (Beijing Research Institute of Nonferrous Metals, Beijing, P. R. China) and a LC column (MP-C18, $250 \mathrm{~mm}$ $\times 4.6 \mathrm{~mm}$ i.d., $5 \mu \mathrm{m}$, Tianjin Bonna-Agela Technique Co., Ltd., Tianjin, P. R. China), was employed to measure the $\mathrm{Hg}$ species in the fish samples for validation of the proposed method according to the Chinese national standard method of GB 5009.17. After injecting the analyte solution, the effluent from the LC column was subjected to $\mathrm{HG}$, where all separated $\mathrm{Hg}$ species were changed to $\mathrm{Hg}^{2+}$ by $\mathrm{K}_{2} \mathrm{~S}_{2} \mathrm{O}_{8}$ under UV irradiation, then reduced to $\mathrm{Hg}^{0}$ by $\mathrm{KBH}_{4}$ in $\mathrm{HCl}$ medium. Subsequently, the generated volatile $\mathrm{Hg}^{0}$ species passed to the AFS by carrier gas for measurement. The instrumental parameters of LC-HG-AFS are shown in Table 2. Ar gas $(99.999 \%, v: v)$, containing $10 \% \mathrm{H}_{2}(99.999 \%$, v:v), was employed to fulfill the atomization of $\mathrm{Hg}$ in AFS. 


\section{RESULTS AND DISCUSSION}

Stannous chloride reaction conditions. Stannous chloride is frequently employed to react with $\mathrm{Hg}^{2+}$ to form the volatile $\mathrm{Hg}^{0}$ species and then remain alkyl mercury, such as $\mathrm{MetHg}^{+}$and $\mathrm{EtHg}^{+}$, in the residual solution. This is the basic principle of MetHg analysis in this work. Thus, the effect of $\mathrm{SnCl}_{2}$ on the $\mathrm{Hg}$ species possibly existing in the fish samples was investigated. Here, $1 \mathrm{~mL}$ of single elemental solution of $\mathrm{Hg}^{2+}, \mathrm{MetHg}^{+}$, and $\mathrm{EtHg}^{+}$and their mixture were employed to react with $1 \mathrm{~mL} 10 \% \mathrm{SnCl}_{2}$ (w:v) solution, respectively. The $3 \% \mathrm{Hg}^{2+}$ recovery obtained (as listed in Table 3 ) shows that more than $97 \%$ was removed from the analyte

Table 3. Effect of $\mathrm{SnCl}_{2}$ on $\mathrm{Hg}$ Species after $\mathrm{Hg}^{2+}-\mathrm{Sn}^{2+}$ Reaction (n=3)

\begin{tabular}{|c|c|c|c|c|}
\hline Sample $^{a}$ & Added $(\mu \mathrm{g} / \mathrm{L})$ & $\begin{array}{l}\text { Residue Measured } \\
(\mu \mathrm{g} / \mathrm{L})\end{array}$ & $\begin{array}{l}\text { RSD } \\
(\%)\end{array}$ & $\begin{array}{l}\text { Recovery }{ }^{b} \\
(\%)\end{array}$ \\
\hline $\mathbf{H g}^{2+}$ & 10 & 0.15 & 12 & $3.0 \pm 0.4$ \\
\hline MetHg & 10 & 4.8 & 4 & $96 \pm 4$ \\
\hline EtHg & 6 & 2.83 & 1 & $94 \pm 1$ \\
\hline Mixed & $\begin{array}{l}10\left(\mathrm{Hg}^{2+}\right) \\
10(\mathrm{MetHg}) \\
6(\mathrm{EtHg})\end{array}$ & 7.8 & 6 & $98 \pm 6$ \\
\hline
\end{tabular}

${ }^{a}$ For $\mathrm{Hg}^{2+}, \mathrm{MetHg}^{+}$, or $\mathrm{EtHg}^{+}, 1 \mathrm{~mL}$ of single elemental solution was mixed with $1 \mathrm{~mL} 10 \% \mathrm{SnCl}_{2}(w: v)$ solution. So, the dilution factor is 2 .

${ }^{\mathrm{b}}$ The recovery is calculated as follows: (Residue measured $\times 2$ )/added $\times$ $100 \%$. For $\mathrm{Hg}^{2+}$, the added is $10 \mu \mathrm{g} / \mathrm{L}$; for MetHg, the added is $10 \mu \mathrm{g} / \mathrm{L}$; for EtHg, the added is $6 \mu \mathrm{g} / \mathrm{L}$; for mixed, the added is $16 \mu \mathrm{g} / \mathrm{L}$ (MetHg + EtHg).

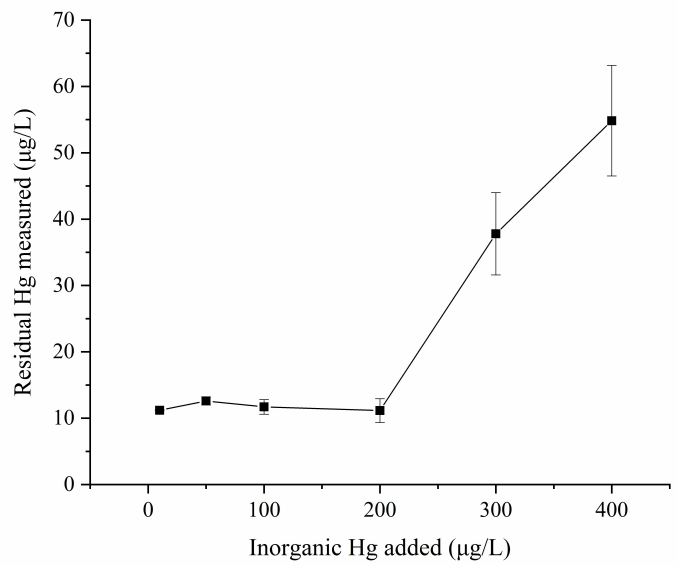

Fig. 2 The tolerance of $\mathrm{SnCl}_{2}$ for $\mathrm{Hg}^{2+}$ concentration in real sample analysis. The $\mathrm{Y}$ axis shows the residual $\mathrm{Hg}$ (alkyl mercury) in solution after 40 -fold dilution during the extraction process. So, the certified $\mathrm{Hg}$ residual concentration should be $12.7 \pm 0.7 \mu \mathrm{g} / \mathrm{L}$ considering MetHg: $507 \pm 28 \mu \mathrm{g} / \mathrm{kg}$. solution; while MetHg and EtHg remained at more than $96 \%$ and $94 \%$, respectively. In addition, the recovery of mixture of $\mathrm{Hg}^{2+}(10$ $\mu \mathrm{g} / \mathrm{L})+\operatorname{MetHg}(10 \mu \mathrm{g} / \mathrm{L})+\mathrm{EtHg}(6 \mu \mathrm{g} / \mathrm{L})$ was $98 \%$ after $\mathrm{SnCl}_{2}$ reaction. It proved that the $\mathrm{Hg}^{2+}-\mathrm{Sn}^{2+}$ reaction using $1 \mathrm{~mL} 10 \%$ $\mathrm{SnCl}_{2}$ (w:v) solution fulfilled the alkyl $\mathrm{Hg}$ residual without significant $\mathrm{Hg}^{2+}$ interference in the standard solution medium.

The tolerance of $\mathrm{SnCl}_{2}$ in real samples. However, the tolerance of $\mathrm{SnCl}_{2}$ for $\mathrm{Hg}^{2+}$ is limited by the $\mathrm{Hg}^{2+}$ presence in real samples. Therefore, a CRM sample of fish tissue (QC457B-2) was prepared according to the sample preparation method mentioned above, where different $\mathrm{Hg}^{2+}$ concentrations were spiked into the extracted analyte solution ready for measurement. As shown in Fig. 2, the measured $\mathrm{Hg}$ presence is in accordance with the certified value of MetHg in the CRM before $200 \mu \mathrm{g} / \mathrm{L} \mathrm{Hg}^{2+}$ spiking, indicating no obvious $\mathrm{Hg}^{2+}$ interference. With an increase in $\mathrm{Hg}^{2+}$ concentration in the range of $>200 \mu \mathrm{g} / \mathrm{L}$, the amount of measured $\mathrm{Hg}$ obviously increased. This was possibly due to excessive $\mathrm{Hg}^{2+}$ which cannot be completely reduced with $1 \mathrm{~mL} 10 \% \mathrm{SnCl}_{2}$ (w:v) solution. Of course, if needed, one can increase the concentration of $\mathrm{SnCl}_{2}$ to enhance the reduction reaction. In practice and considering a 40fold dilution obtained during sample preparation, it is impossible that $8 \mathrm{mg} / \mathrm{kg}$ (approximately $200 \mu \mathrm{g} / \mathrm{L} \times 40$ ) $\mathrm{Hg}^{2+}$ would exist in real fish samples. As a result, $1 \mathrm{~mL} 10 \% \mathrm{SnCl}_{2}(w: v)$ solution was used for MetHg analysis in real fish samples.

Determination of $\mathrm{Hg}^{2+}$ species in real fish samples. The subtraction method adopted to detect $\mathrm{MetHg}^{+}$was coupled to the CVAAS, where $\mathrm{MetHg}^{+}=$total $\mathrm{Hg}-\mathrm{Hg}^{2+} \cdot{ }^{28,29}$ However, the proposed method enables the direct analysis of MetHg after $\mathrm{Hg}^{2+}$ $\mathrm{Sn}^{2+}$ reaction. Based on reverse thinking, the $\mathrm{Hg}^{2+}$ present in the fish samples can be obtained via the calculation $\mathrm{Hg}^{2+}=$ total $\mathrm{Hg}-$ $\mathrm{MetHg}^{+}$. Thus, total $\mathrm{Hg}$ must first be measured by the direct sampling $\mathrm{Hg}$ analyzer. It is another advantage that direct sampling $\mathrm{Hg}$ analyzer is capable to measure total $\mathrm{Hg}$ in real fish sample without digestion process.

To investigate the feasibility of $\mathrm{Hg}^{2+}$ calculation, a real fish sample was employed to determine the total $\mathrm{Hg}$ and $\mathrm{MetHg}$ concentrations with different $\mathrm{Hg}^{2+}$ spikes. As shown in Table 4, the dominating $\mathrm{Hg}$ species in this real fish sample is MetHg, accounting for $61 \%-79 \%$, which is consistent with other studies. ${ }^{25,30}$ In addition, the $\mathrm{Hg}^{2+}$ spike recoveries are at different levels ranging from $99 \%-104 \%$, proving favorable accuracy for inorganic $\mathrm{Hg}$ analysis by the proposed method. However, $\mathrm{Hg}^{2+}$ is not the main target species of this work but can be applied when needed.

Table 4. Recovery Analysis of $\mathrm{Hg}$ Species in Fish Samples (n=3)

\begin{tabular}{|c|c|c|c|c|c|}
\hline Sample & $\begin{array}{l}\text { Measured MetHg } \\
(\mu \mathrm{g} / \mathrm{kg})\end{array}$ & $\begin{array}{l}\text { Add } \mathrm{Hg}^{2+} \\
(\mu \mathrm{g} / \mathrm{kg})\end{array}$ & $\begin{array}{l}\text { Total Hg } \\
(\mu \mathrm{g} / \mathrm{kg})\end{array}$ & $\begin{array}{l}\text { Calculated } \mathrm{Hg}^{2+} \\
(\mu \mathrm{g} / \mathrm{kg})^{\mathrm{a}}\end{array}$ & $\begin{array}{l}\text { Recovery } \\
(\%)\end{array}$ \\
\hline \multirow{3}{*}{ Sea bass } & & 0 & $28.7 \pm 1.1$ & 5.9 & - \\
\hline & $22.8 \pm 2.6$ & 50 & $80.6 \pm 2.9$ & 51.9 & $104 \pm 4$ \\
\hline & & 200 & $227.4 \pm 8.5$ & 198.7 & $99.4 \pm 3.7$ \\
\hline Fish CRM (QC457B-2) & $491 \pm 8$ & 0 & $808 \pm 26$ & 317 & - \\
\hline
\end{tabular}


Table 5. Comparison of This Proposed Method with Others Reported Previously

\begin{tabular}{|c|c|c|c|c|c|}
\hline Methods & Sample & LOD & Analysis time (min) & Recovery (\%) & Ref. \\
\hline GC-ICP-MS & Fish & $0.3 \mu \mathrm{g} / \mathrm{kg}$ & 200 & $87-117$ & 2 \\
\hline HS-SPME-GC-PD-OES & Hair & $\begin{array}{l}\mathrm{Hg}^{2+}: 0.35 \mu \mathrm{g} / \mathrm{kg} \\
\text { MetHg: } 1 \mu \mathrm{g} / \mathrm{kg}\end{array}$ & 220 & $85-93$ & 4 \\
\hline LC-ICP-MS & Blood & $\begin{array}{l}\mathrm{Hg}^{2+}: 0.02 \mathrm{ng} / \mathrm{g} \\
\text { MetHg: } 0.04 \mathrm{ng} / \mathrm{g}\end{array}$ & 17 (instrumental analysis) & $80-95$ & 6 \\
\hline MSPE-HPLC-ICP-MS & Fish/water & $\begin{array}{l}\mathrm{Hg}^{2+}: 0.74 \mathrm{ng} / \mathrm{kg} \\
\text { MetHg: } 0.67 \mathrm{ng} / \mathrm{kg}\end{array}$ & 795 & $81-118$ & 8 \\
\hline LC-PVG-AFS & Fish/hair & MetHg: $1.06 \mu \mathrm{g} / \mathrm{kg}$ & 55 & $93-105$ & 9 \\
\hline HPLC-CV-AFS & Fish & $\begin{array}{l}\mathrm{Hg}^{2+}: 0.6 \mu \mathrm{g} / \mathrm{kg} \\
\text { MetHg: } 0.56 \mu \mathrm{g} / \mathrm{kg}\end{array}$ & 600 & $98-103$ & 10 \\
\hline FI-DBD-AAS & Fish & $\begin{array}{l}\mathrm{Hg}^{2+}: 0.35 \mathrm{ng} / \mathrm{g} \\
\text { MetHg: } 0.54 \mathrm{ng} / \mathrm{g}\end{array}$ & 41 & $95-106$ & 11 \\
\hline CV-AFS & Mushroom & $\begin{array}{l}\mathrm{Hg}^{2+}: 0.6 \mathrm{ng} / \mathrm{g} \\
\text { Total } \mathrm{Hg}: 3.2 \mathrm{ng} / \mathrm{g}\end{array}$ & - & $94-104$ & 29 \\
\hline HPLC-ICP-MS & Fish/water & $\begin{array}{l}\mathrm{Hg}^{2+}: 15 \mathrm{ng} / \mathrm{kg} \\
\text { MetHg: } 17 \mathrm{ng} / \mathrm{kg}\end{array}$ & 300 & $93-114$ & 31 \\
\hline ETV-amalgamation-AAS & Fish & $\begin{array}{l}\text { MetHg method LOD: } 0.6 \mu \mathrm{g} / \mathrm{kg} \\
\text { Absolute LOD: } 3 \mathrm{pg}\end{array}$ & $\begin{array}{l}\text { The whole time: } 100 ; \\
\text { Instrumental analysis: }<5\end{array}$ & $85-106$ & This work \\
\hline
\end{tabular}

Analytical performances. Under the optimized conditions, the analytical figures of merit were evaluated. The linearity of the calibration curve was investigated by measuring a series of standard solutions ranging from $0-20 \mathrm{ng}$ in long light path and $20-500 \mathrm{ng}$ in short light path, and with linear regression coefficients $\left(R^{2}\right)$ of 0.999 and 1, respectively. The absolute LOD and limit of quantification (LOQ) for MetHg was $3 \mathrm{pg}$ and $10 \mathrm{pg}$, respectively, calculated by taking 3 or 10 times the standard deviation of the blank solution divided by the slope of the calibration from 11 repeated measurements. So, the method's LOD and LOQ was $0.6 \mu \mathrm{g} / \mathrm{kg}$ and $2 \mu \mathrm{g} / \mathrm{kg}$ using $0.2 \mathrm{~mL}$ sample size (maximum loading for sampling boat of direct sampling $\mathrm{Hg}$ analyzer), respectively, and considering a 40-fold dilution. Actually, the proposed analytical sensitivity is comparable to LCAFS, proving a promising application for fast screening analysis of MetHg in fish samples. The RSDs for MetHg in real samples (salmon, cod, Trachinotus ovatus, and flatfish) were in the range of $0.4 \%-6.3 \%$, indicating good analytical precision. In addition, the recoveries for marine (Larimichthys crocea, spiked with 120 , 240 , and $480 \mu \mathrm{g} / \mathrm{kg} \mathrm{MetHg}$ ) and freshwater (mandarin fish, spiked with 20,40 , and $80 \mu \mathrm{g} / \mathrm{kg}$ MetHg) fish samples ranged from $85 \%$ to $106 \%$, demonstrating favorable analytical accuracy.

In Table 5, this proposed method is compared to previously reported literature. The instrumental $\mathrm{LOD}$ of $\mathrm{Hg}$ using the direct sampling $\mathrm{Hg}$ analyzer was comparable to CV-AFS or CV-AAS, but inferior to ICP-MS analysis. However, in spite of the dilution factor from the sample preparation, the established method LOD $(0.6 \mu \mathrm{g} / \mathrm{kg})$ is competent to the fast detection of MetHg in fish samples. If necessary, some preconcentration approaches, such as MSPE, SPME, etc. (Table 5), can be utilized to pre-concentrate analyte to enhance the detection capacity of MetHg.
The proposed method's analytical time including sample preparation and instrumental analysis time was $<100 \mathrm{~min}$, of which the sample preparation of extraction, purification and reaction process accounts for $>90 \mathrm{~min}$. Thus, $100 \mathrm{~min}$ is less than used with most of methods listed in Table 5. It is more important that the practical analysis time using the direct sampling $\mathrm{Hg}$ analyzer requires only $\sim 3 \mathrm{~min}$, which is obviously shorter than that by the LC methods. So, several dozen samples can be processed in one batch by the proposed method, leading to a significant time savings for real sample analysis in comparison to the LC methods.

Method validation and real sample analysis. To validate the feasibility of the proposed method, several real fish samples were used. The presence of alkyl $\mathrm{Hg}$ was determined in all samples by the established method $(n=3)$ as well as the LC-AFS method in accordance with the Chinese national standard method of GB 5009.17. As shown in Table 6, the relative deviations between the proposed method and the LC-AFS standard method or certified values are from $0.8 \%$ to $3.0 \%$ in real marine and freshwater fish samples. In addition, there is no significant difference $(P>0.05)$ between the proposed method and the LC-AFS method. Their results show favorable consistency of MetHg analysis with the certified or standard method values. The whole analytical time, including sample preparation can be accomplished within $100 \mathrm{~min}$, verifying fast analysis of alkyl $\mathrm{Hg}$ including MetHg in real fish samples. In addition, the results in Table 6 show that the MetHg levels in freshwater fish are obviously lower than in marine fish samples, which is in agreement with other previous reports. ${ }^{25,30} \mathrm{It}$ can, therefore, be stated that the proposed method is a fast screening method for MetHg presence in fish samples. When also MetHg and EtHg speciation analysis is required, LC atomic spectrometry can be further utilized. 
Table 6. Determination of MetHg Species in Real Fish Samples (n=3)

\begin{tabular}{|c|c|c|c|c|c|}
\hline Sample & $\begin{array}{l}\text { The proposed method } \\
(\mu \mathrm{g} / \mathrm{kg})\end{array}$ & $\begin{array}{l}\text { LC-AFS or certified } \\
(\mu \mathrm{g} / \mathrm{kg})\end{array}$ & $\begin{array}{l}\text { Relative deviation } \\
(\%)\end{array}$ & Pvalue ${ }^{a}$ & $\begin{array}{l}\text { Recovery }^{b} \\
(\%)\end{array}$ \\
\hline $\begin{array}{l}\text { Fish CRM } \\
\text { (QC457B-2) }\end{array}$ & $491 \pm 8$ & $507 \pm 28$ & 0.8 & 0.457 & 97 \\
\hline $\begin{array}{l}\text { Trachinotus Ovatus } \\
\text { (Marine) }\end{array}$ & $135 \pm 6$ & $136 \pm 1$ & 1.0 & 0.676 & 99 \\
\hline $\begin{array}{l}\text { Larimichthys crocea } \\
\text { (Marine) }\end{array}$ & $268 \pm 5$ & $275 \pm 5$ & 1.8 & 0.319 & 97 \\
\hline $\begin{array}{l}\text { Snapper } \\
\text { (freshwater) }\end{array}$ & $36.3 \pm 1.0$ & $35.3 \pm 2.0$ & 3.0 & 0.488 & 103 \\
\hline $\begin{array}{l}\text { Mandarin fish } \\
\text { (freshwater) }\end{array}$ & $35.5 \pm 1.1$ & $36.7 \pm 1.9$ & 2.4 & 0.531 & 97 \\
\hline
\end{tabular}

\section{CONCLUSIONS}

The direct sampling $\mathrm{Hg}$ analyzer was utilized in this report for the fast measurement of MetHg in fish samples by employing stannous chloride reduction. After the simple reduction reaction, $\mathrm{Hg}^{2+}$ was changed to volatile $\mathrm{Hg}^{0}$ and vaporized from the analyte extraction solution. Based on the results, the residual $\mathrm{Hg}$ species can be quickly determined by direct sampling $\mathrm{Hg}$ analyzer regardless of chromatographic separation. Because the dominating organic $\mathrm{Hg}$ in fish tissue is mostly $\mathrm{MetHg}$, therefore, for fast screening analysis the measured alkyl $\mathrm{Hg}$ residue can be used as a measure for the MetHg presence. The proposed method achieved $0.6 \mu \mathrm{g} / \mathrm{kg}$ LOD with good precision. The analytical sensitivity is comparable to results by LC-AFS or LC-CVAAS and furthermore, sample preparation and testing can be accomplished within $100 \mathrm{~min}$. On the other hand, the $\mathrm{Hg}^{2+}$ presence in the fish samples can be calculated by subtracting the total $\mathrm{Hg}$ and alkyl $\mathrm{Hg}$ values. This proposed method no doubt has considerable potential for fast screening $\mathrm{Hg}$ speciation. Considering the detrimental effect on humans from MetHg in fish, this proposed method should be used for rapid screening analysis to protect food safety.

\section{AUTHOR INFORMATION}

\section{Corresponding Author}

*X. F Mao

Email address: mxf08@163.com; maoxuefei@caas.cn

\section{Author Contributions}

${ }^{\bar{\top}} \mathrm{S}$. Q. Li and C. C. Hao contributed equally to this work.

\section{Notes}

The authors declare no competing financial interest.

\section{ACKNOWLEDGMENTS}

This investigation was funded within the Central Public-interest Scientific Institution Basal Research Fund (No. Y2019XK05/1610072018003), Agricultural Science and Technology Innovation Program of CAAS (No. CAASZDRW202011), and National Key Research and Development Program of China (No. 2016YFF0103306). As well, sincerest thanks to the support of the Agricultural Science and Technology Innovation Program presided over by Yongzhong Qian.

\section{REFERENCES}

1. S. L. Colla, S. E. Botté, and J. E. Marcovecchio, Mar. Pollut. Bull., 2019, 140, 40-50. https://doi.org/10.1016/j.marpolbul.2018.12.051.

2. S.W. C. Chung and B. T. P. Chan, J. Chromatogr. A, 2011, 1218, 1260-1265. https://doi.org/ 10.1016/j.chroma.2010.12.112.

3. Y. Gao, S. D. Galan, A. D. Brauwere, W. Baeyens, and M. Leermakers, Talanta, 2010, 82, 1919-1923. https://doi.org/10.1016/j.talanta.2010.08.012.

4. Y. Yang, Q. Tan, Y. Lin, Y. Tian, L. Wu, X. Hou, and C. Zheng, Anal. Chem., 2018, 90, 11996-12003. https://doi.org/10.1021/acs.analchem.8b02607.

5. J. Li, Q. He, L. Wu, J. Sun, F. Zheng, L. Li, W. Liu, and J. Liu, Microchem. J., 2020, 153, 104459-104489. https://doi.org/10.1016/j.microc.2019.104459.

6. Y. Sogame and A. Tsukagoshi, J. Chromatogr. B-Bio. Med. Appl., 2020, 1136, 121855-121884. https://doi.org/10.1016/j.jchromb.2019.121855.

7. A. Londonlo, P. E. Hasuoka, P. Pacheco, R. A. Gil, and P. Smichowski, J. Anal. At. Spectrom., 2018, 33, 1737-1744. https://doi.org/10.1039/C8JA00188J.

8. S. Zhu, B. Chen, M. He, T. Huang, and B. Hu, Talanta, 2017, 171, 213-219. https://doi.org/10.1016/j.talanta.2017.04.068

9. P. Coufalík, N. Meszarosová, K. Coufalíková, O. Zvěřina, and J. Komárek, Microchem. J., 2018, 140, 8-13. https://doi.org/10.1016/j.microc.2018.03.040

10. A. C. Grijalba, P. Y. Quintas, E. F. Fiorentini, and R. G. Wuilloud, J. Anal. At. Spectrom., 2018, 33, 822-834. https://doi.org/10.1039/C8JA00059J. 
11. Z. Zhu, Z. Liu, H. Zheng, and S. Hu, J. Anal. At. Spectrom., 2010, 25, 697-703. https://doi.org/10.1039/b924824b

12. E. Covaci, M. Senila, M. Ponta, E. Darvasi., M. Frentiu, and T. Frentiua, Food Control., 2017, 82, 266-273. https://doi.org/10.1016/j.foodcont.2017.07.006.

13. R. Jagtap and W. Maher, Microchem. J., 2015, 121, 65-98. https://doi.org/10.1016/j.microc.2015.01.010.

14. J. R. Miranda-Andrades, S. Khan, M. J. Pedrozo-Penãfiel, K. de C. B. Alexandre, R. M. Maciel, R. Escalfon, M. L. B.Tristão, and R. Q. Aucelio, Spectrochim. Acta B., 2019, 158, 105641105651. https://doi.org/10.1016/j.sab.2019.105641.

15. B. Wang, L. Feng, X. Mao, J. Liu, C. Yu, L. Ding, S. Li, C. Zheng, and Y. Qian, J. Anal. At. Spectrom., 2018, 33, 1209-1216. https://doi.org/10.1039/c8ja00009c.

16. Y. M. Panta, S. Qian, C. L. Cross. and J. V. Cizdziel, J. Anal. Appl. Pyrol., 2008, 83, 7-11. https://doi.org/10.1016/j.jaap.2008.05.006

17. T. P. Liu, M. T. Liu, J. X. Liu, X. F. Mao, S. S. Zhang, Y. B. Shao, X. Na, G. Y. Chen. and Y. Z. Qian, Anal. Chim. Acta, 2020, 1121, 42-49. https://doi.org/10.1016/j.aca.2020.04.057.

18. U.S. EPA, 2007. EPA Method 7473, Environmental Monitoring and Support Laboratory. Cincinnati, $\mathrm{OH}, 45268$.

19. W. Wohlmann, V. M. Neves, G. M. Heidrich, J. S. Silva, A. B. D. Costa, J. N. G. Paniz. and V. L. Dressler, Spectrochim. Acta B, 2018, 149, 222-228. https://doi.org/10.1016/j.sab.2018.08.009.

20. C. P. Chou, T. C. Chang, C. H. Chiu. and H. C. His, Aerosol. Air Qual. Res., 2018, 18. 2801-2812. https://doi.org/10.4209/aaqr.2018.05.0205.
21. M. Aramendía, A. Guarda, D. Leite. and M. Resano, J. Anal. At. Spectrom., 2017, 32, 2352-2359. https://doi.org/10.1039/C7JA00323D.

22. I. D. L. Calle, I. Lavilla, H. Bartolomé-Alonso. and C. Bendicho, Spectrochim. Acta B, 2019, 161. 105697-105706. https://doi.org/10.1016/j.sab.2019.105697.

23. N. A. Panichev, and S. E. Panicheva. Food Chem., 2015, 16, $432-441$. https://doi.org/10.1016/j.foodchem.2014.06.032

24. C. E. Oda and J. D. Ingle, Anal. Chem., 1981, 53, 2305-2309. https://doi.org/10.1021/ac00237a040.

25. M. Lemes and F. Wang, J. Anal. At. Spectrom., 2009, 24, 663-668. https://doi.org/10.1039/b819957b.

26. T. J. Mathews, B. B. Looney, A. L. Bryan, J. G. Smith, C. L. Miller, G. R. Southworth. and M. J. Peterson, Chemosphere., 2015, 138, 190-196. https://doi.org/10.1016/j.chemosphere.2015.05.083.

27. GB 5009.17. National Health and Family Planning Commission of P. R. China. 2014.

28. D. Li, Y. Li and X. Wang, J. Environ Sci., 2018, 68, 177-184. https://doi.org/10.1016/j.jes.2018.02.017.

29. M. Ruiz-De-Cenzano, O. López-Salazar, M. L. Cervera. and M. D. L. Guardia, Anal. Method., 2016, 8, 1774-1779. https://doi.org/10.1039/C5AY03227J.

30. S. T. Lancaster, C.-C. Brombach, W. T. Corns, J. Feldmann, and E. M. Krupp, J. Anal. Atom. Spectrom., 2019, 34, 1166-1172. https://doi.org/ 10.1039/C9JA00037B.

31. S. Patricia, L. Agustín, H. P. Emir, and G. R. Andres, J. Anal. At. Spectrom., 2018, 33, 1737-1744. https://doi.org/10.1039/C8JA00188J.

CRC Press/Routledge/Taylor \& Francis announces the availability of:

\section{Measuring Heavy Metal Contaminants in Cannabis and Hemp}

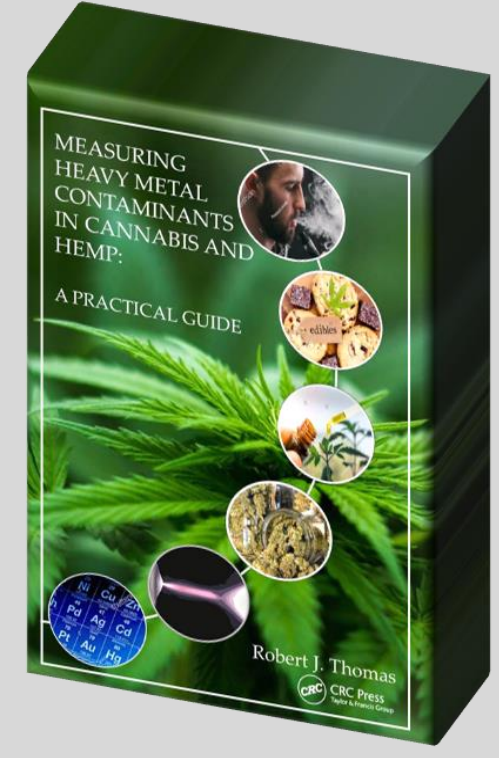

Available September, 2020

ISBN: 9780367417376
Robert J. Thomas, CSci, CChem, FRSC Principal Consultant Scientific Solutions, Gaithersburg, MD www.scientificsolutions1.com

The complete guide to measuring elemental contaminants in cannabis and hemp for growers, cultivators, processors, testing labs and regulators.

Offers guidance to cultivators and processors to better understand the sources of heavy metals in cannabis.

For state regulators, it compares maximum contaminant limits of heavy metals with those for federally-regulated pharmaceutical materials.

For testing labs, it describes fundamental principles and practical capabilities of ICP-MS, ICP-OES, AA and AF for measuring heavy metals in cannabis.

Suggests strategies to characterize heavy metals in vaping liquids and aerosols

Covers the important role of other analytical techniques for the comprehensive testing of cannabis products 